\title{
Huellas del pasado en las culturas escolares
}

\section{Signs of the Past in School Cultures}

\author{
Elsie ROCKWELL \\ Centro de Investigación y de Estudios Avanzados. México \\ erockrich@yahoo.com
}

Recibido: 24 de octubre de 2006

Aceptado: 31 de enero de 2007

\begin{abstract}
Resumen
Retomando un concepto antropológico que subraya la dinámica histórica de la cultura, el artículo sostiene que las culturas escolares pueden comprenderse en términos de la paulatina selectiva apropiación de diversos recursos culturales. Para ello, examina prácticas observadas hacia finales del siglo XX, en las primarias de una región de México con fuerte presencia nahua. El análisis de entrevistas y registros de clase muestra la influencia de consignas y reformas educativas generadas en distintos momentos del siglo, así como efectos de sucesivos libros de texto. Las clases observadas también reflejan la incorporación de recursos discursivos y saberes propios de la región. La historicidad de la práctica escolar permite cuestionar la existencia de una "cultura escolar" constante y uniforme. Aconseja más bien realizar cuidadosos estudios comparados.
\end{abstract}

Palabras clave: México, antropología de la educación, historicidad, teoría de cultura, culturas escolares, discurso en el aula.

\begin{abstract}
Assuming an anthropological concept that underscores the historical dimension of culture, the article argues that school cultures can be understood in terms of the selective and progressive appropriation of diverse cultural resources. To sustain this position, it examines practices observed towards the end of the twentieth century in elementary schools of a Nahuatl region of Mexico. Analyses of interviews and classroom transcripts reveal the influence of educational precepts and reforms introduced during the whole century, including the effects of successive textbooks. Practices also reflect the incorporation of discursive and cultural resources from the region. The historicity of school practices would challenge the existence of a constant and uniform "culture of schooling" and rather advises undertaking careful comparative research.
\end{abstract}

Key words: Mexico, Anthropology of education, historicity, culture theory, school cultures, classroom discourse.

Sumario: 1. Introducción. 2. Apoyos conceptuales. 3. Continuidades y rupturas con la tradición decimonónica. 4. Huellas de la época de oro de la escuela rural mexicana. 5. Una idea racional y exacta del universo y del mundo social. 6. La influencia del IFCM en las maneras de hablar. 
7. Los libros "de la patria": reflejo y molde de una cultura magisterial. 8. Los libros de la Reforma: dilemas del descubrimiento. 9. Reflexiones finales. 10. Referencias bibliográficas.

\section{Introducción}

Desde la perspectiva antropológica, se concibe la educación como un entramado de procesos de transmisión, reproducción, apropiación y transformación de objetos, saberes y prácticas culturales en contextos diversos que siempre rebasan la instrucción formal. La investigación etnográfica ha resaltado la gran diversidad de contenidos y formas que asumen estos procesos humanos universales. Ha constatado que las dinámicas históricas de la cultura en espacios educativos, como en otros dominios -parentesco, asentamiento, trabajo, celebración, autoridad-, están sujetas a juegos y tramas de poder -legitimación, dominación, resistencia, coerción-, e involucran tanto continuidades como rupturas a lo largo del tiempo. La visión antropológica sobre la educación en sociedades escolarizadas ha logrado esclarecer planos de conflicto, de correspondencia y de influencia mutua entre las prácticas culturales que ocurren en las escuelas y aquellas que caracterizan los entornos locales y los flujos globales. No obstante, si bien muchos trabajos han abordado las relaciones entre la experiencia escolar y el entorno social, existe cierta tendencia a dejar el estudio de la interacción entre maestros y alumnos a otras disciplinas, como la didáctica y la psicología educativa y, sobre todo, el análisis del discurso. Estas disciplinas recurren de manera creciente a conceptos socio-culturales; sin embargo, suelen tratar lo cultural como atributo del contexto, de los contenidos o de los educandos, pero rara vez como una dimensión inherente a las prácticas educativas mismas.

En este trabajo argumento que las configuraciones de herramientas, prácticas y saberes que se conjugan dentro de las aulas pueden comprenderse desde la lógica de los procesos culturales. Evitando la mirada que intenta evaluar las consecuencias de políticas educativas o prescripciones pedagógicas, abordo lo que ocurre en las escuelas con la intención de comprender su dinámica cultural e histórica. Intento mostrar cómo podría repensarse el análisis de lo que ocurre en las aulas en términos de la acumulación y la sedimentación de distintos recursos culturales introducidos a lo largo de un siglo. Para dejar testimonio de esta dinámica, examino la historicidad de prácticas que pude observar hacia finales del siglo XX, en las escuelas primarias de varios pueblos de La Malintzi, Tlaxcala- región de México marcada por una fuerte presencia nahua. La investigación retoma por una parte registros de clases de primaria y entre- 
vistas que realicé durante la década de los ochenta y, por otra, tratados pedagógicos y documentos de archivo que muestran formas de enseñanza propuestas y difundidas en la región a lo largo del siglo Xx. Intenta mostrar que en la práctica de cada maestro se distinguía la influencia de diversas reformas y consignas educativas, así como los efectos de la introducción de dispositivos pedagógicos, en particular de los libros de texto gratuitos, distribuidos en México desde los años sesenta del siglo pasado. Más allá de las huellas de las sucesivas reformas, las clases observadas también reflejaban la incorporación de recursos culturales y discursivos propios de la región.

\section{Apoyos conceptuales}

Al abordar el mundo escolar desde la antropología, se vuelve ineludible trabajar con el concepto de cultura, en alguna de sus múltiples acepciones. William Sewell, un historiador que utiliza la teoría antropológica, ofrece una síntesis útil de la discusión actual en torno a este concepto polisémico que se encuentra en constante curso de redefinición. Observa que actualmente es "ilusorio" concebir una pluralidad de culturas como entidades discretas, "lógicamente consistentes, altamente integradas, consensuales, resistentes al cambio y claramente delimitadas" (Sewell, 2005:171) ${ }^{1}$. Enfatiza, en cambio, el hecho de que las configuraciones culturales son más bien contradictorias internamente e incluyen elementos y significados que son objeto de disputa social. El análisis de la dimensión cultural, lejos de señalar sistemas cerrados, revela configuraciones que están "flojamente acopladas", delimitadas por fronteras difusas y permeables. Estas configuraciones además "están sujetas a cambios constantes", tienen historia (Sewell, 2005: 169-171). Sewell agrega que no es posible suponer que las culturas poseen una coherencia inherente y esencial; las configuraciones culturales adquieren cierta coherencia relativa sólo en función de su vinculación con diversas instancias sociales que concentran el poder y que intentan "organizar la diversidad", dando lugar a de cierta unidad temporal (Sewell, 2005:171-174). Las instituciones educativas, entre otras, son instancias que tienden a proyectar cierta "coherencia cultural”, aunque en realidad están atravesadas por contradicciones, conformadas de capas sedimentadas y abiertas a múltiples flujos culturales externos. Desde esta concepción, resulta difícil hablar de una "cultura escolar" correspondiente a una institución circunscrita y universal. Las tramas culturales de

1 Traducción de la autora. 
las escuelas son construcciones históricas y, como tales, muestran encadenamientos y transformaciones en el tiempo ${ }^{2}$. Están sujetas a flujos culturales provenientes de diversos ámbitos, ante los cuales muestran diferentes grados de permeabilidad y de clausura.

Para abordar esta dimensión cultural en contextos educativos, es importante integrar algunos conceptos adicionales. En la tradición de la teoría histórico-cultural ${ }^{3}$, el trabajo pedagógico implica el uso de "herramientas y signos", acumulados de manera desigual en diferentes sectores, momentos y tiempos -que se objetivan, se apropian y se utilizan dentro de determinadas prácticas culturales-. En los contextos escolares, estas prácticas incluyen formas más o menos convencionales de actuar, hablar, trabajar, disciplinar, tratar a los niños, representar el conocimiento y mostrar el saber, que se reproducen a menudo más allá de las acciones planeadas o las intenciones conscientes del maestro. A partir de estas tramas culturales, los maestros integran recursos pedagógicos diversos de manera selectiva a lo largo de sus vidas. Además, expresan o incorporan continuamente modos de hablar y representar los saberes que nunca han sido prescritos para las escuelas, pero que se entreveran con las tradiciones pedagógicas. Por lo tanto, el trabajo docente no refleja de manera coherente la normatividad pedagógica vigente.

Las pautas de cambio y continuidad de las prácticas y los saberes escolares no se rigen del todo desde los dispositivos normativos puestos en marcha por las autoridades institucionales. Las culturas escolares tienen una dinámica propia, en la que el encuentro entre personas de diferentes generaciones -maestros, padres y jóvenes- condiciona ritmos y formas de transmisión intergeneracional, de apropiación y de resistencia, que no respetan los tiempos económicos y políticos. Tiene poco sentido por ello contrastar realidades escolares con los modelos prescriptivos expresados en textos del periodo del estudio; es seguro que no habrá una correspondencia nítida. En cambio, es posible encontrar dentro de un corte temporal la influencia parcial y paulatina que han tenido diversos dispositivos oficiales a lo largo de décadas.

No es fácil distinguir las huellas del pasado en la multiplicidad de prácticas y significados culturales que se observan en un contexto escolar en un

\footnotetext{
2 Sobre un concepto plural de "culturas escolares", me he inspirado sobre todo en los trabajos de Julia, 1995; Nespor, 1997; Chervel, 1998; Viñao, 1999; Escolano, 2000; Chartier, 2003, 2005; Lawn y Grosvenor, 2005. Ver también Rockwell, 1997.

3 Esta tradición remite sobre todo a Lev Vygotsky y a M. M. Bajtín, y a la investigación que se ha realizado utilizando sus teorías.
} 
momento dado. Para apoyar esta tarea, he recurrido al concepto de cronotopo, con el cual Bajtín buscaba: “... la plenitud y la claridad de los signos visibles del tiempo en el espacio... y el carácter creativamente activo del tiempo -del pasado en el presente-...”. (Bajtín, 1982: 234). Bajtín señalaba que Goethe:

distribuía las cosas que se encuentran juntas en el espacio según los eslabones temporales, según las épocas de generación. Para él, lo contemporáneo, tanto en la naturaleza como en la vida humana, se manifiesta como una diacronía esencial: o bien como residuos... de diversos grados de desarrollo y de las formaciones del pasado, o bien como gérmenes de un futuro más o menos lejano (Opus cit.).

Entre las herramientas culturales utilizadas en el aula, cobran especial importancia las prácticas discursivas y los usos de textos escritos. Para abordar estas prácticas, ha sido útil la reflexión del mismo autor sobre los géneros discursivos. Bajtín incluía como géneros no sólo las formas convencionales de escribir, como la novela o el sermón, sino también cualquier manera de hablar, como las formas de saludarse o interrogarse, siempre cargadas de antemano de múltiples sentidos dados los usos pretéritos de las mismas palabras y formulaciones. Reconocía que los hablantes y los escritores retoman, mezclan y transforman los géneros disponibles de manera creativa, imprimiéndoles acentos y tonos, según la situación. Proponía que existen ciertos “ambientes genéricos", espacios sociales en los cuales la fuerza colectiva moldea el discurso, orientándolo hacia determinadas formas y censurando otras. Las instituciones educativas, como otras, han favorecido, o bien excluido, el desarrollo de determinados géneros, formando en los educandos y docentes disposiciones hacia ciertas maneras de hablar y de escribir, que varían a través del tiempo/espacio y que se diversifican según los niveles y las modalidades escolares.

Desde esta concepción, es posible pensar que los maestros hablan y escriben de maneras que son producto de tendencias genéricas diversas que han prevalecido en los ámbitos de formación y de trabajo docente a lo largo de sus vidas. Desde luego, lo hacen de manera selectiva, adaptando los diversos recursos según su propio estilo y valoración, pues los géneros se renuevan en cada realización; "recuerdan su pasado pero viven en el presente" (Bajtín, 1984:106). Se forma así una larga cadena que permite explicar la continuidad de ciertas prácticas transmitidas de generación a generación de maestros, así como la aparición de recursos textuales y discursivos retomados o inventados por los propios maestros. 
Bajtín sugirió que los géneros de habla forman "correas de transmisión" entre la historia del lenguaje y la historia de la sociedad (Bajtín, 1986: 66). Así, los géneros pueden constituir puentes para vincular el análisis del discurso del aula y la historia social de las culturas escolares. Esta perspectiva aporta una dimensión histórica al discurso oral y escrito, y desde luego a los gestos, las posturas y las acciones ${ }^{4}$, que observamos en las clases. Es con esta perspectiva que propongo examinar un conjunto de prácticas culturales observadas en primarias de la zona de La Malintzi, intentando distinguir las sedimentaciones producidas por los ambientes y los sucesos educativos que generaron las maneras de enseñar en los años ochenta del siglo pasado.

\section{Eslabones temporales en las tradiciones docentes}

Frente a la homogeneidad de las normas y los dispositivos nacionales -leyes, programas y libros- en México durante la época del estudio (19801992), resaltaba la heterogeneidad de las culturas escolares reales. Muchas prácticas pedagógicas arraigadas en la región de La Malintzi eran distantes de las formas de trabajo prescritas en los discursos pedagógicos de la época. Dentro de la diversidad, era posible distinguir algunos patrones recurrentes en la región. Los géneros utilizados por los maestros de estas escuelas reflejaban las tradiciones regionales y nacionales de enseñanza e incluso formas de expresión locales no escolares. Muchas de las prácticas sin duda eran compartidas por otros maestros e incluso reflejaban corrientes pedagógicas que trascendían las fronteras nacionales ${ }^{5}$. Sin embargo, algunas similitudes entre los maestros sugerían tradiciones docentes locales.

Al hablar de tradiciones docentes, intento eliminar el matiz peyorativo del término tradición, para identificar componentes de diversas tradiciones docentes específicas que se arraigaban en la región. En muchos escritos sobre educación se confronta lo tradicional con lo moderno, con un sesgo valorativo pero con pocas referencias históricas. Mientras lo tradicional se asocia con ideas como el "verbalismo" y la disciplina estricta, lo moderno sugiere lo "innovador" y reclama como rasgo propio la atención a los niños como sujetos pensantes. Estos calificativos polares ocultan diferencias significativas entre las prácticas observadas, mejor comprendidas como expresión de tradiciones docentes diver-

\footnotetext{
4 La perspectiva "multimodal” desarrollada por Gunther Kress, Carie Jewitt y otros (2001) está explorando estos aspectos.

5 Katie Anderson-Levitt (2002) describe traslapes entre culturas pedagógicas nacionales transnacionales para el caso de Francia y Estados Unidos, algunos son similares a su vez con México.
} 
sas. Algunas tradiciones podrían identificarse con reformas que fueron introducidas en distintos momentos; retomaron consignas pedagógicas que fueron innovadoras en su momento y conformaron culturas docentes complejas y cambiantes. En las clases observadas, algunas prácticas remitían a temporalidades muy largas, otras estaban comprendidas en la memoria histórica local; otras más eran construcciones recientes o emergentes ${ }^{6}$.

Las prácticas observadas provenían de los cruces entre las trayectorias de vida de los maestros y los sucesivos flujos culturales y pedagógicos que habían entrado al ámbito local. Al comparar maestros de diferentes generaciones, era posible intuir cómo algunas maneras de enseñar se habían incorporado con fuerza, mientras que otras tendían a perderse o permanecían marginales. Había ciertas tendencias generacionales que reflejaban discontinuidades en las prácticas culturales en estas escuelas. Sin embargo, no siempre existía una relación lineal entre la edad de un maestro y su forma de trabajo. Algunos maestros mayores se habían apropiado recursos introducidos por las sucesivas reformas educativas. Por otra parte, los maestros jóvenes hacían uso de recursos pedagógicos antiguos, heredados de sus propios mentores. La práctica de cada maestro incluía formas codificadas por generaciones anteriores junto con expresiones y técnicas recientes. Los maestros participaban de ciertas tradiciones reconocibles, sin embargo también desarrollaban estilos personales de trabajar. Al apropiarse los recursos pedagógicos que habían llegado a la región, les imprimían su sello personal. Además, algunos maestros introducían en el aula maneras de hablar propias de las comunidades de las que eran originarios. Como cada uno combinaba recursos de diferentes orígenes, no es posible armar una tipología nítida o clasificar a los maestros según tradiciones. Más bien, se trataba de seguir vetas que aparecían y se ocultaban en el quehacer cotidiano del aula.

Al mirar la práctica de los maestros como una composición de diferentes planos, cada uno con cierta continuidad en el tiempo, es posible empezar a desatar algunos de los hilos que forman las tradiciones docentes. Para establecer los antecedentes, fue necesario rastrear algunos de los "ambientes genéricos", para retomar el concepto de Bajtín, que influyeron en la vida y el trabajo de los maestros de la región. Al reconstruir la historia de reformas educativas y de las instituciones de formación docente intenté sopesar su influencia relativa

\footnotetext{
6 Doy una explicación más amplia de esta perspectiva en Rockwell, 1999, texto en el que propongo articular tres planos en el análisis de las clases, para recuperar la dimensión histórica junto con la cotidiana.
} 
dentro de la zona de estudio, pues aun las acciones estatales tendientes a "uniformar la educación" tienen efectos diferenciales en distintas regiones. Diversas fuentes y documentos me permitieron encontrar algunos vínculos efectivos entre el presente y el pasado. Algunas fuentes mostraban cómo determinadas instituciones con presencia duradera en el estado de Tlaxcala incidieron directa o indirectamente en generaciones de maestros. Las entrevistas con algunos maestros sugerían que habían incorporado a su trabajo prácticas que observaron en sus mentores y aludían a la procedencia de algunas de sus preferencias. Ciertos textos provenientes de determinadas épocas pasadas aún proveían recursos que utilizaban los maestros en sus clases. Finalmente, algunas prácticas o géneros parecían responder a corrientes subterráneas que sobrevivieron de alguna manera a lo largo del siglo, sin ser promovidas oficialmente.

En las siguientes secciones, examino huellas fragmentarias de algunos eslabones temporales vinculados con las reformas educativas y las corrientes de pensamiento pedagógico que pudieran haber influido en la vida de los maestros de la región. El recorrido empieza por identificar las similitudes y diferencias que podrían existir entre las formas de enseñanza de principios del siglo Xx y la práctica observada en la región durante los años ochenta. Muestro algunos géneros orales nombrados en documentos que se perdieron o mantuvieron a lo largo del siglo. A continuación, hago un recuento de algunas prácticas vinculadas a la introducción de las reformas posrevolucionarias -la escuela rural mexicana y la educación socialista- y a los ámbitos de formación de los maestros, incluyendo las conferencias pedagógicas y las acciones destinadas a maestros en servicio. Examino los efectos de la fuerte ruptura que ocurrió con la distribución gratuita de los primeros juegos de libros de textos oficiales a todos los niños, durante los años sesenta. Muestro cómo la transformación radical de estos libros durante la Reforma Educativa (1970-1976) planteó nuevos dilemas frente al uso del texto ${ }^{7}$. El análisis se suspende antes de la llamada modernización educativa de 1992, que posteriormente habrá ejercido su propia influencia material y normativa sobre las prácticas docentes en las primarias de la región.

Los cortes se refieren a momentos claves en la historia, aunque es seguro que algunas recomendaciones de cada reforma continuaron estando presentes en la formación de las sucesivas generaciones de maestros. Así, por ejemplo, las ideas sobre la escuela rural que se forjaron después de la revolución se reproducían en las normales rurales durante décadas después de que habían dejado de ser polí-

7 Sobre esta historia, González Pedrero, 1982. 
ticas vigentes. Las consignas pedagógicas tuvieron efectos que rebasaban los momentos en que aparecían inicialmente en el discurso oficial.

En este artículo, he centrado el análisis en las maneras de hablar y de leer en clase, señalado algunas de las diversas combinaciones encontradas en la práctica. En la variedad de maneras de usar la palabra y los textos es posible encontrar rasgos que remiten a las reformas pedagógicas procuradas en diferentes momentos del siglo $\mathrm{XX}^{8}$. El análisis se sesga hacia aquellas clases que permitían registrar una mayor gama de maneras de hablar y trabajar con los textos. Retomo ejemplos de los grados superiores de la primaria, de la materia de lengua -español-, pero también de otras materias escolares dentro de las cuales se trabajaba con la lectura y la discusión. Fue particularmente interesante seguir las diversas propuestas para la enseñanza de las ciencias, ya que tuvieron una influencia importante en la selección y el uso de géneros textuales y discursivos.

Como cuestión central, señalo la disyuntiva entre el uso de la palabra oral y el recurso al texto escrito que marca todo el siglo. A lo largo del recorrido señalo momentos de tensión entre ciertos géneros discursivos y la referencia a textos impresos. Esta veta permite captar momentos en que penetran el aula diversas expresiones y conocimientos regionales retomados por los maestros o por los alumnos. Algunas tradiciones daban mayor cabida a la incorporación de elementos de la experiencia cotidiana al proceso de enseñanza, frente a la tendencia a privilegiar la formulación textual codificada en diversos recursos escolares. El juego entre ambas tendencias muestra los límites de la "coherencia relativa" de la cultura escolar y revela sus contradicciones internas.

\section{Continuidades y rupturas con la tradición decimonónica}

A finales del siglo XIX, el intento de promover una pedagogía objetiva o intuitiva en México se oponía a una cultura escolar donde predominaba el uso de catecismos religiosos o cívicos ${ }^{9}$. Las nuevas consignas pedagógicas orientaban a los maestros hacia la vida real y desestimaban el uso de libros de textos ${ }^{10}$. Esta tendencia tuvo una expresión particular ligada a la reciente incorporación

\footnotetext{
8 La influencia de sucesivos debates y políticas educativas en torno a la lectura y la escritura, y sus influencias en las culturas escolares, han sido tema de otros estudios, notablemente, los de A-M. Chartier, 2003, 2005, y A-M Chartier y Hébrard, 1989.

9 Los pedagogos mexicanos del siglo XIX, como Carrillo, Flores y Rebsamen, retomaron corrientes modernas de la pedagogía europea, sin embargo elaboraron propuestas originales.

10 Rockwell, 2002, se centra en este debate y sus efectos en la práctica.
} 
de temas de ciencias naturales en la enseñanza elemental. Entre otras cosas, a los maestros de aquel tiempo se les recomendaba acercarse a la naturaleza y dar lecciones de cosas, para que los niños aprendieran a conocer su mundo (Carri1lo, 1964: 693-704). Aunque existían en el medio textos con el título Lecciones de Cosas, hay poca evidencia empírica de cómo se llevó a la práctica la enseñanza objetiva en las escuelas. Algunos maestros tlaxcaltecas de principios del siglo habían concluido la primaria superior y el año de estudios pedagógicos en el Instituto Científico y Literario en Tlaxcala, fundada a finales del siglo XIX, donde podrían haber conocido el amplio acervo del gabinete de historia natural. No obstante, los docentes del Instituto parecen haber preferido el uso de textos a la experiencia directa con los objetos expuestos. En todo caso, no existían estos recursos en las demás escuelas del Estado.

En las fuentes documentales es posible encontrar algunas pistas sobre las maneras de enseñar recomendadas a los maestros en servicio en aquella época. Aunque no existen trazas del discurso real en las aulas, se conservan textos que prescribían formas de hablar. Es el caso del protocolo de una clase modelo que se dio en 1917, en el contexto de la capacitación de maestros en servicio en la región ${ }^{11}$. La lección, de 25 minutos, fue sobre el tema de un tipo de flor, el aretillo, utilizado como el objeto en torno al cual se daría la clase dentro de la tradición de las "lecciones de cosas". El protocolo registraba la siguiente secuencia, sin dar mayores detalles:
I. Recordatorio de la clase anterior
II. Enunciación del tema
III. Conversación sobre el tema
IV. Catecismo dirigido a los alumnos sobre el tema.
V. Resumen oral por el maestro
VI. Resumen oral por los estudiantes

Esta descripción dista mucho de ser un registro de lo que pasó, pero es interesante en varios sentidos. El fragmento menciona varios géneros -la conversación, el catecismo, el resumen oral- que se conservaban o introducían al inicio del siglo Xx. Un primer rasgo notable de este esquema ideal es el predominio de la participación oral, tanto del maestro como de los

\footnotetext{
11 Reseña de la conferencia verificada el sábado veinticinco del mes de agosto de mil novecientos diecisiete en el salón destinado a la Escuela elemental de Santa Cruz, Tlaxcala y bajo la presidencia del C. Inspector Técnico-Administrativo de la Segunda Zona Escolar, Profesor Bernabé Barrera. Archivo General del Estado, Fondo de la Revolución y el Régimen Obregonista, caja 344/3, 1917.
} 
alumnos. La clase se abría y cerraba con presentaciones orales: el recordatorio, la enunciación y los resúmenes. Entre ambos, se nombran dos géneros que regulaban el intercambio oral con los alumnos. En lo que se llamaba conversación, seguramente no mediaba ningún texto. El uso de un catecismo sugiere la existencia de un texto con preguntas y respuestas preestablecidas, no obstante, es difícil imaginar que hubiera uno sobre la planta del aretillo.

Cuando realicé las observaciones durante la década de los ochenta, algunos maestros mayores en la región parecían responder a la consigna de privilegiar el modo oral. Sobresalía un maestro ya próximo a la jubilación, Fidencio $^{12}$, quien había terminado la educación elemental -formalmente de cuatro grados-, el nivel más alto que existía en los años veinte en los pueblos de la región. A lo largo de los años, él había tomado varios cursos de pedagogía; sin embargo, no se había inscrito en los programas de titulación. Su práctica se distinguía por un marcado uso público de la palabra. Para él, lo importante era lograr que los pequeños "le perdieran el miedo de hablar en clase". En todas las materias, solía componer un pequeño texto o problema sobre el pizarrón y luego pasar a los alumnos a "darle lectura" en voz alta varias veces, antes de copiarlo en sus cuadernos. Si se trataba de resolver un problema o contestar una pregunta, pedía a los alumnos que primero dijeran en voz alta los pasos que seguían o lo que pensaban escribir. Fidencio insistía en que los niños debían aprender "a pensar". Como me comentaba, "siempre he sabido que es necesario razonar para aprender, que uno tiene que inducir a los estudiantes a hablar, para poder enseñarles a pensar". Si bien es posible que su forma de trabajar reflejara una amalgama construida a lo largo de los años, resaltaba el énfasis en la palabra oral. El contraste entre esta tradición y la práctica de otros maestros mostraba una de las diferencias marcadas dentro de la trama cultural general en estas escuelas.

Al tener como referencia las categorías del protocolo de 1917 para examinar las prácticas observadas, es posible reconocer algunas continuidades y cambios a lo largo del siglo Xx. Los dos pasos iniciales, recordatorio y enunciación, parecen ser bastante familiares. Durante los años ochenta, era común que los maestros comenzaran por recordar la clase anterior y enunciar el tema que tratarían. Esto a menudo significaba dar una definición del término, como sucedió en una clase en que el maestro Pablo pregunta la

12 Los nombres de este maestro y los demás referidos en este artículo son ficticios. 
definición del tema: “...ustedes me van a decir, en primer lugar, la pregunta que les hice, ¿qué quiere decir ecología?” Acepta varias respuestas, antes de reformularlas con la frase altamente codificada: "es la ciencia que estudia los seres...? (suspende en tono de preguntar)". A esta pregunta los alumnos contestan a coro: "vivos". Luego el maestro precisó y amplió el sentido del término. De manera similar, otros maestros iniciaban un tema con una breve explicación o definición del tema, como "la investigación" o "la oración". Si bien ahora "enunciar el tema" pareciera ser un paso de sentido común, es importante recordar que esta práctica tiene una historia relacionada con la paulatina construcción de una secuencia programática común para los alumnos de un grado escolar, considerado como un grupo homogéneo. Este desarrollo es relativamente reciente y aún no caracteriza a todas las escuelas de México, ni del mundo. De hecho, en 1917 enunciar un tema común en las escuelas unitarias - multigrado- que predominaban en la región podría haber sido bastante problemático.

Para los años ochenta, parecía ser menos común el resumen oral al final de una clase, pues muchos maestros terminaban dando o dictando una conclusión escrita. En ninguna clase observada se pidió un resumen oral a los alumnos, como se sugiere en el protocolo, aunque los maestros a veces construían una conclusión a partir de las respuestas de los alumnos. El maestro Rodrigo, al terminar una clase sobre el ciclo del agua, solicitó una conclusión oral. Después de cuestionar la frase escueta, “...el agua va y viene”, que ofreció un alumno, aceptó una versión más elaborada y más cercana al lenguaje del texto escrito: “...el agua sube en forma de vapor y forma nubes, y luego cae en forma de lluvia...". Escribió la frase en el pizarrón para que la copiaran. Otros maestros de la región intentaban de manera similar llegar a una conclusión mediante un interrogatorio a los alumnos. Sin embargo, a menudo este ejercicio oral se suspendía después de algunos minutos, para dar lugar al cuestionario escrito, como cierre más común.

En el protocolo de 1917, el término que suena más fuera de lugar para los años ochenta es catecismo, dispositivo que los educadores del siglo XIX retomaron de la Iglesia para inculcar una conciencia cívica nacional. Esta forma genérica, proveniente de la Reforma y la Contrarreforma, se había adoptado después de la revolución francesa para diseñar catecismos civiles y llegó a México con la Independencia ${ }^{13}$. A pesar de su asociación con el método

13 Tanck de Estrada, 1977: 220-232. Ver ejemplos en Razo, 2000. 
socrático ${ }^{14}$, los diálogos, cómo se les llamaba a veces, habían acabado en series fijas de preguntas y respuestas prescritas que pretendían facilitar el trabajo de los preceptores. Durante el siglo XIX, el catecismo fue criticado por los pedagogos, tanto por sus antecedentes doctrinarios como por la repetición literal del texto. Con el nacimiento de las Normales y el giro hacia la enseñanza objetiva ${ }^{15}$, se cuestionaba la memorización de textos. Enrique C. Rebsamen, prestigiado pedagogo suizo quien radicaba en México ${ }^{16}$, afirmó de manera tajante: "La Pedagogía moderna ha condenado para siempre el uso de los textos en forma catequística". No obstante, él mantenía la asociación entre la mayéutica y la manera de "preguntar catequizando", para designar una forma de interrogación que el maestro hace a los alumnos "con el fin de que descubran por sí mismos la verdad que trata de inculcarles" (Rebsamen, 2001:173, 182) $)^{17}$.

El término catecismo seguía presente en el discurso normativo local a principios del siglo XX como muestra el protocolo de $1917^{18}$. En este caso, posiblemente se usaba para designar la manera de preguntar sugerida por Rebsamen. De hecho, las críticas hacia la memorización de respuestas aparecían en el mismo documento, que concluye con la siguiente nota:

El inspector recomendó que los profesores pusieran atención a la manera en que se dirigían las preguntas a los estudiantes; no debían inculcar las respuestas de memoria, salvo en el caso de las recitaciones. Deben evitar, en lo posible, las respuestas a coro, y deberían poner en práctica las clases modelo en sus propias escuelas.

Al reprobar la memorización y la respuesta coral, salvo en el caso de las recitaciones, el inspector de 1917 reconocía las críticas al uso del catecismo. Algunas de estas críticas se seguían expresando décadas después. En las clases observadas en los ochenta en la región tlaxcalteca, la interrogación seguía siendo el eje de gran parte del trabajo. Aún se encontraban ocasionalmente respuestas a coro, que uno podría pensar eran una reminiscencia de la tradición que se

14 Algunos autores relacionan este género con los diálogos socráticos. Sin embargo, Sócrates hacía todo menos procurar una respuesta preestablecida en un texto.

15 En México, las nuevas concepciones pedagógicas en esta línea se asocian con la obra de Manuel Flores, 1901.

16 Entre otras acciones, Rebsamen había fundado la Normal de Veracruz en Jalapa, donde se habían formado varios educadores del estado contiguo de Tlaxcala a finales del siglo XIX.

17 La raíz griega significaba simplemente enseñar por la vía de la palabra oral.

18 Durante los años treinta todavía se llegó a proponer un "Catecismo socialista”, texto que fue rechazado por Rafael Ramírez. 
combatía a principios de siglo. De hecho, era difícil evitar las respuestas a coro, cuando la pregunta así lo indicaba implícitamente. Sin embargo, algunos maestros lo desalentaban. El maestro Pablo hacía eco de las críticas antiguas cuando insistía: "no contesten a coro... pidan la palabra... ¿me entienden?".

A pesar de la incidencia de las respuestas a coro, el catecismo era una influencia genérica relativamente distante sobre las formas de enseñar de los años ochenta. El término catecismo como referencia a un método de enseñanza ya no se usaba entre maestros de la región. A pesar de la naturaleza ritual de algunos intercambios con los alumnos, ningún maestro usaba una serie fija de preguntas y respuestas prescritas. La variedad de preguntas utilizadas abría un abanico de respuestas posibles, aunque a menudo los maestros las orientaban hacia la formulación que esperaban.

De hecho, se observaba una tensión entre prácticas interrogativas que intentaban producir las respuestas previstas y el género de conversación recomendado por pedagogos desde el siglo XIX, y también presente en el protocolo de la lección del aretillo de 1917. Rebsamen también había hecho recomendaciones al respecto: “. . .cuando el maestro entabla una conversación con sus alumnos, debe dejarse un tiempo amplio a la espontaneidad de su espíritu, debe dejarles en libertad de contestar con su propio lenguaje, que es distinto en cada niño..." (Rebsamen, 2001:182). Esta disyuntiva parece ser una constante en todo intento de hacer hablar a los alumnos. Los propios niños percibían el conflicto entre decir lo que pensaban y dar con la respuesta esperada por el maestro. No obstante, en algunas clases, se abrían paréntesis que realmente acercaban el intercambio a una conversación, por la disposición del maestro a aceptar las intervenciones diversas de los alumnos. Por ejemplo, en la clase sobre el ciclo del agua, Rodrigo inició un intercambio, un poco al margen del tema central, sobre los pozos del pueblo, en el cual los alumnos aportaban información acerca de su profundidad y condición que él desconocía, invirtiendo así la pauta acostumbrada ${ }^{19}$. La conversación aparecía como un género discursivo que abría espacios para la expresión de saberes no escolares, formulados de manera relativamente espontánea, tanto por parte de los alumnos como por el maestro.

En otros momentos, la interacción conducía hacia la producción de la respuesta esperada. Aunque ésta no siempre estaba prefigurada como tal en un texto, como era el caso con los catecismos impresos, sí tendía a reflejar las

19 Analizo esta secuencia en Rockwell, 1991. 
normas de formulación escrita más que de conversación, como se nota en el ejemplo citado arriba de la conclusión sobre el ciclo del agua. En estas secuencias, la palabra oral tendía a reproducir o a reflejar los géneros escritos, cerrando el paso a los saberes locales.

A pesar de que el texto de 1917 sugiere una realidad escolar conocida, tenía poco que ver con las formas de enseñar de los maestros que observé en los años ochenta. Sólo quedaba en este tiempo una práctica que podría vincularse a esta tradición: la recitación de versos. Justamente esa práctica había escapado a la tendencia a desalentar el uso de la memorización. Su paulatina desaparición hacia finales del siglo Xx fue un último paso para desprestigiar la memoria dentro de la cambiante cultura escolar de la región. El predominio de la palabra oral que se percibe en el protocolo, y en algunos maestros mayores, parecía desplazarse poco a poco por la referencia al texto impreso. A pesar de estos cambios, muchos maestros continuaban asociando su oficio con el uso de la voz y sosteniendo que no son los libros, sino son las personas quienes expresan el conocimiento.

\section{Huellas de la época de oro de la escuela rural mexicana}

En la práctica de muchos maestros de la región, se observaba la influencia de otra corriente pedagógica, distinta a la que se había codificado en la estructura del catecismo y las lecciones de cosas. Durante la época posrevolucionaria (1921-1934) en México, se habían difundido las críticas hacia una escolarización que se limitaba a ofrecer los "rudimentos de la cultura". Los educadores que diseñaban la nueva escuela rural mexicana en ese tiempo ${ }^{20}$ rechazaban la enseñanza 'libresca' a favor de la 'enseñanza para la vida'. Proponían enseñar cosas necesarias para "el progreso de la civilización campesina”. En este contexto, Rafael Ramírez ampliaba las críticas hacia prácticas basadas en la repetición memorística del texto (Ramírez, 1937: 129-130). Agregaba a ello la dimensión de la acción: "El maestro debe pues, poner al niño en condiciones tales que pueda...hacer las cosas por sí mismo. Esto quiere decir que las nociones sobre las diferentes asignaturas...deben darse sobre el propio terreno, en los momentos en que el alumno trabaja..." (Ramírez, 1986: 41). Estas nuevas ideas poco a poco entraron a la región, para competir con la tradición del Instituto Científico y Literario, particularmente desde la nueva normal rural federal fundada en Xocoyucan, Tlaxcala, y desde los cursos orga-

20 Educadores como Rafael Ramírez, Moisés Sáenz, Enrique Corona, entre otros. 
nizados por la Misión Cultural de la Secretaria de Educación Pública para actualizar a los maestros en servicio ${ }^{21}$.

A partir de estas recomendaciones, muchos maestros del Estado difundían prácticas sociales, productivas y artísticas que dependían en gran medida del discurso oral. Favorecían el trabajo práctico, pero también el deporte y las representaciones teatrales. Los educadores intentaban que su trabajo fuera relevante tanto para forjar patria como para promover el progreso en las regiones rurales. Recogían elementos del siglo anterior que servían a ese fin, particularmente el énfasis en la higiene que había marcado a toda una época. La enseñanza se subordinaba a este proyecto, tomando como punto de partida los centros de interés y los proyectos prácticos que se establecían en las escuelas.

Durante los años ochenta, la intención de establecer un estrecho vínculo entre la escuela y la comunidad se había abandonado hacía tiempo, sin embargo algunos géneros difundidos en la región durante esa época se podían identificar en el discurso de los maestros. Pese a la urbanización progresiva de la zona, la imagen de una comunidad rural y sus costumbres seguía presente. Algunos problemas y ejemplos planteados por los maestros aludían a situaciones características del medio rural. El maestro Alberto, de Santa Cruz, organizó a sus alumnos para representar una obra referida a un campesino que no quería enviar a su hijo a la escuela, hecho que entonces casi no ocurría. En otra ocasión relacionó el tema de la comunicación no verbal con la costumbre aún vigente de usar los tambores para llamar a la fiesta patronal. Otros maestros retomaban saberes locales expresados por los niños. La maestra Celia dio una clase sobre hierbas medicinales, en la que incorporó ejemplos que habían traído sus alumnos de casa; algunos nombres eran poco conocidos desde la escuela, como axomiate, estafiate, epazote morado y hierba del zorrillo. Fue notorio que estos ejemplos permanecieran en lo oral y no formaran parte de la lista escrita en el pizarrón, que incluía manzanilla, romero, ruda e hinojo.

Los maestros de los años ochenta intentaban además influir en la realidad local, orientando a los alumnos hacia nuevas prácticas. Varios ejemplos se encuentran en la clase de ecología que dio Pablo, quien era nativo de la región. La clase incluía un repaso de lo que los alumnos habían aprendido durante una visita a una casa ecológica experimental instalada en el pueblo.

21 En mi estudio histórico sobre los años 1910 a 1940 (Rockwell, 2007) describo las consecuencias locales de estas reformas. 
El siguiente comentario de Pablo resonaba con la consigna de los años veinte, de relacionar los temas escolares con las necesidades de las comunidades y de inculcar nuevos hábitos domésticos. En este caso, se trataba del fogón elevado que habían conocido durante la visita.

Pablo: ...bueno... en la casa ecológica... [el fogón] evita el cansancio de las personas que hacen tortillas... ¿no?... en el caso de su mamá... su hermana...o a lo mejor a ustedes.... ¿quién de ustedes hace tortillas ahí en su casa? ... levanten bien la mano... sin vergüenza ninguna... esos es... que se siente hacer tortillas... ahí hincadas... ¿se siente bonito?

As: ... ¡no!

Pablo: no... se cansan las rodillas

As: sí...

Pablo: se cansan las rodillas... y luego ¿qué se cansa?

As: ...la espalda...

Pablo: ... la espalda ¿verdad?... y aparte de eso... ¿quién nos hace llorar?...

As: ¡el humo!

Pablo: el humo... si quieren... luego después les cuento un cuento de Quetzalcóatl (y el humo)

Pablo no sólo intentaba orientar a los alumnos hacia nuevas prácticas domésticas. También aludía a la historia cultural prehispánica, antecedente lejano de la cultura local, al ofrecer un cuento en el cual Quetzalcóatl ${ }^{22}$ le recomendó a su madre que si acaso llegara a llorar por su ausencia dijera que era a causa del humo. La referencia a este tipo de leyendas tenía cierto arraigo especial en la región de La Malintzi, tanto dentro como fuera de la escuela, si bien las versiones provenían más de obra plástica y textos impresos que de la tradición oral. La intervención de Pablo reflejaba la consigna de vincular la escuela con la vida, que era reconocida por muchos maestros de la región, aunque ya pocos pusieran en práctica los ambiciosos proyectos comunitarios de los años veinte. En esta tradición, en particular, los saberes locales se expresaban en el aula en los momentos de apertura discursiva.

\section{Una idea racional y exacta del universo y del mundo social}

El lema de la educación socialista, una idea racional y exacta del universo y del mundo social, fue elevado al rango constitucional en el Artículo $3^{\circ}$ constitucional vigente entre 1934 y 1944. Con ello, se estableció que todo alumno

22 Quetzalcóatl, un personaje prehispánico semi-mítico, se asociaba durante el periodo colonial con Santo Tomás, quien habría llegado antes de los españoles a preparar la conversión al Catolicismo. Esta asociación y las leyendas correspondientes, eran particularmente fuertes en Tlaxcala. 
de primaria tenía derecho al conocimiento científico del mundo natural y social, destituyendo así las distinciones existentes entre la educación destinada a niños y niñas, al medio urbano y al medio rural. En Tlaxcala, la consigna se reinterpretó a partir de una tradición liberal y republicana ligada a la escuela pública decimonónica. El objetivo enunciado en el artículo constitucional se entendió como un combate a las creencias tradicionales y un énfasis en la utilidad de la ciencia, aspectos que influyeron en la cultura escolar de esta región.

El reflejo de esta tendencia seguía visible en las escuelas durante los años ochenta, particularmente en los momentos que privilegiaban la explicación y la comprensión de los temas de ciencias. En varias clases, las explicaciones acerca del sistema solar o de las vacunas se relacionaban con críticas a las creencias locales acerca de los eclipses y las enfermedades. Aludiendo a creencias locales, Pablo hizo el siguiente comentario acerca de los conejos:

Pablo:...no aguanta uno el olor a al conejo... inclusive... las creencias de los pueblos... ¿no?... que (los conejos) hacen bastante daño a las niñas... iporque no sé qué! ... ¡icreo que no se casan!... o no sé qué pasa... allá dicen, ¡no!......pero nos falta técnica... al contrario (el orín) ¡hasta ayuda a desinfectar!

Pablo se sumaba a la tarea de "erradicar las supersticiones", una orientación que, si bien fue introducida desde el siglo XIX, fue intensificada durante los años treinta. También reflejaba esta tradición al decir que el agua contaminada podía secar las milpas, "aunque -agregaba- tienden a culpar a dios". El énfasis que se había introducido con la educación socialista consistió en siempre dar explicación científica a las recomendaciones prácticas, lo cual seguía siendo válido. Como lo decía el maestro Felipe: “¿por qué los regaño cuando traen las manos sucias?, porque cuando vamos a defecar al campo, tomamos muchos microbios en las manos. Luego esa tierra trae microbios y las traemos en las manos, por eso hay que lavárselas".

Una particularidad del periodo de la educación socialista fue una diseminación más amplia de la palabra impresa. Durante esta época, la SEP respaldó y difundió los primeros libros de lectura de alcance nacional. Más aún, publicó y distribuyó muchos textos para apoyar el trabajo de los maestros. La parte del magisterio vinculada a los movimientos políticos de izquierda se volcó hacia la lectura, incorporando a su acervo personal no solamente herramientas propias de su trabajo sino también tratados económicos, legales y políticos, instructivos prácticos y literatura nacional y extranjera. La nueva relación con la palabra impresa influyó en la práctica, pues abrió vías de acceso a otras fuentes de 
información y de opinión. El maestro Macario recordaba: "En esa época no era como ahora con los libros de texto. Teníamos que estudiar varios libros para de allí sacar todo lo que enseñábamos".

Entre los maestros de los años ochenta quedaban pocos que se hubieran formado durante el auge de los años treinta, aunque algunos seguían expresando las posturas militantes de la época. En cambio, entre muchos permanecía la tendencia a buscar textos y folletos de muy diverso tipo que apoyaran su trabajo, incluyendo compendios legales, folletos turísticos sobre zonas arqueológicas, antologías poéticas y semblanzas de los héroes. Transformar la información sacada de estos textos en un relato oral para los alumnos o en un pequeño resumen escrito representaba parte de la preparación de sus clases.

La tradición de la educación socialista se encaminaba hacia la formación de una conciencia científica y una identidad nacional secular. Aunque la reforma de 1934 pronto fue derogada por su contenido socialista, el impulso que dio a las maneras de entender la cultura y la ciencia y de traducirlo para todo ciudadano duraría la mayor parte del siglo Xx. Su impacto en el ámbito cultural de la región fue significativo, si bien se incorporó a una matriz de tradiciones muy diversas. A la larga, la orientación socialista compartía el espacio con expresiones de religiosidad popular, muy arraigadas en la zona de $\mathrm{La}$ Malintzi, así como con la amplitud de información y desinformación que se difundía por los nuevos medios masivos de comunicación. Nuevamente, las apropiaciones realizadas dentro de las aulas, mediadas por los maestros, influyeron en la configuración cultural local, para regresar años después al aula como "saberes locales"23. La comprensión de los eclipses ya era tan común que los niños la expresaban en clase. La conciencia de la explotación de los trabajadores, en cambio, había sido desplazada en gran medida por las elaboraciones ideológicas que borraron la historia de la época socialista.

\section{La influencia del IFCM en las maneras de hablar}

La mayoría de los maestros que trabajaba en las escuelas del estado durante los años ochenta había estudiado en el Instituto Federal de Capacitación del Magisterio (IFCM) fundado en $1945^{24}$. La formación de los maestros en servicio que no habían cursado la Normal quedó en manos de los normalis-

\footnotetext{
23 Ver Chervel, 1998, sobre la manera en que las culturas escolares influyen en las configuraciones culturales de la sociedad.

24 Según datos de los ochenta, más del $60 \%$ se había titulado en esa modalidad.
} 
tas que daban clase en el Instituto y que manejaban un acervo de técnicas didácticas y recomendaciones pedagógicas forjadas después de la revolución. En las clases sabatinas del Instituto, a lo largo de treinta años, se habían consolidado ciertas maneras de enseñar que a su vez influyeron en la práctica de los maestros tlaxcaltecas.

Las entrevistas con algunos de los maestros de la región daban idea de esta experiencia formativa. Al relatar su vida profesional, Pablo contó que después de probar varios oficios y estudios comerciales, tuvo la oportunidad, como muchos otros, de ser contratado como maestro aunque sólo tenía estudios de secundaria y algunos cursos de preparatoria. Ya en el servicio, recorrió varias escuelas en el Estado y se inscribió en el IFCM. De su experiencia en el Instituto, recordaba a los profesores que más le habían impresionado. Todos eran de "edad avanzada". Unos se distinguían por ser buenos para platicar sobre un tema sin referirse a libros o apuntes, otros por saber dar "una explicación amplia" de los contenidos.

Pablo: ...su modo de trabajar era... de llegar y nos platicaba mucho...pero sin que viéramos o abriéramos los libros... toda la hora nos empezaba a platicar porque también se lo sabía de memoria, los movimientos corporales del niño... en la lactancia... todo eso nos explicaba, ... a como nos iba platicando, lo que íbamos captando... íbamos tomando apuntes... nunca nos pidió un libro de psicología... nos llegaban fascículos... son muy buenos, hasta ahora todavía nos sirven, del IFCM... fascículos con apuntes sintetizados... -Después continúa sobre la maestra de ciencias naturales-... esa maestra... hacía mucho material de ese bien dibujadito... bien pintadito... con sus temas bien ordenaditos... nos ponía el rotafolio... nos iba explicando... nos iba dando el tema... nos iba explicando, mire... se nos quedaba... no hablaba mucho pero con los dibujos... y con los términos que ella le daba... captábamos más rápido...

Lo interesante es que plática y explicación coincidían con dos géneros discursivos que Pablo había destacado explícitamente en clase. Por ejemplo, pidió a los alumnos que "platicaran" algo sobre la visita que habían hecho a la casa ecológica. Reiteró varias veces esta petición: “¿nos pueden platicar algo sobre la cocina ecológica?” Durante la plática Pablo utilizó y aceptó varios términos en la antigua lengua local, el náhuatl, para hablar de aspectos relacionados ${ }^{25}$. Aunque no usó el término conversación, con el término plática aludía a un género discursivo similar, en el cual los alumnos se sintieran con más libertad de expresarse. Más tarde, inició con otro tono de voz una secuencia diciendo: “...bueno... vamos a ver... primero que nada... la expli-

25 Para los años ochenta, ya muy pocos niños hablaban el náhuatl, sin embargo, numerosos términos sobrevivían en el español cotidiano. 
cación sobre la cocina ecológica... ¿qué nos decía la bióloga?” Mientras agregaba preguntas puntuales, iba construyendo con las respuestas de los niños una explicación detallada de su funcionamiento ${ }^{26}$.

Es posible que estas dos cualidades asociadas con los maestros, la habilidad de platicar y la capacidad de dar amplias explicaciones sobre los temas, fueran incorporadas a la cultura docente local como modos preferidos de enseñar. El ambiente genérico del IFCM sin duda influyó en la formación tanto de Pablo como de muchos otros docentes de la región. La combinación de un elaborado uso de la expresión oral, incluso para enseñar temas que se encontraban en libros o folletos accesibles, parecía distinguirse de prácticas de los maestros más jóvenes quienes se basaban en los libros de texto.

El uso de la explicación oral requería hacer presente, mediante algún medio, el fenómeno natural del que se hablaba. En las referencias al IFCM aparecen varios ejemplos del uso del dibujo y las ilustraciones, como recursos que tuvieron mayor arraigo en la cultura escolar que el uso de objetos reales promovido por la propuesta decimonónica de lecciones de cosas. Así, al describir las clases de la maestra de ciencias del Instituto, Pablo resaltaba su colección de láminas que ella había hecho a mano y que le servían como punto de partida para explicar los temas. De manera similar, él había utilizado el dibujo a mano de la cocina ecológica como referente para su explicación. El siguiente detalle muestra su forma de proceder.

-Mientras el maestro empezaba a dibujar el horno sobre el pizarrón, los estudiantes gritaban detalles-.

Alumnos: -varios- ¡la silla!... ¡el metate!

Maestro: el metate...más o menos así es... ¿no?

Alumnos: -a coro-: ¡sí!

Maestro: bueno... bueno... ¿no somos artistas...¿no?... ahora síganle.

-Antonio empezó a agregar partes al dibujo, y otros estudiantes ofrecían pasar al pizarrón. Una niña se levanta y va a agregar detalles, junto con Antonio. Otros gritan sugerencias o correcciones.-

Maestro: bueno... ¿qué más le falta?

El dibujo como habilidad escolar cobró fuerza en México con la enseñanza Normal y los Colegios de Artes y Oficios, durante el siglo XIX ${ }^{27}$. La representación convencional de figuras geométricas, los fenómenos geográficos, la

\footnotetext{
26 En Rockwell, 2000, ofrezco un análisis más amplio de este contraste, y en Rockwell, 2001b, considero la expresión de plática en el contexto comunitario.

27 El uso del dibujo había sido parte de la reacción en contra de la enseñanza libresca, asociada con educadores como Pestalozzi.
} 
botánica y la anatomía se convirtieron en parte importante del repertorio docente. Sin embargo, su incorporación a la enseñanza elemental era mucho más lenta; por ejemplo, no se mencionaba en el protocolo de 1917, posiblemente porque se usaría la planta real. Después de la época revolucionaria, hubo iniciativas importantes para la enseñanza del dibujo, sin embargo, en la región no solía considerarse como materia oficial de la primaria elemental, aunque aparecía periódicamente como recomendación a los maestros.

Cuando llegaron a las escuelas primarias los primeros libros de texto gratuitos, en los años sesenta, el dibujo era materia de los grados superiores; sin embargo, lo que aparece en esos libros son ejercicios de dibujo técnico. En los libros de la Reforma Educativa de los años setenta, vigentes en los años ochenta, en cambio, la práctica del dibujo brillaba por su ausencia. Por alguna vía extraoficial perduró la tradición de representar objetos del conocimiento escolar mediante dibujos hechos a mano con trazos convencionales. Durante los años ochenta era práctica común entre maestros mayores de la región, como Fidencio y Eufemio, quienes solían pedir a sus alumnos que calcaran o trazaran a mano el mapa de Tlaxcala. También maestros más jóvenes recurrían a ello, si bien las temáticas eran diferentes: los alumnos de Eduardo habían dibujado a Emiliano Zapata -caudillo de la revolución- para algún concurso local. Todo ello indicaba la formación de una tradición escolar que se transmitía de generación a generación a pesar de que las prescripciones oficiales no siempre la habían alentado.

No obstante, este tipo de dibujo libre empezó a enfrentar una difícil competencia, la aparición de láminas y estampas impresas que se compraban en cualquier papelería. Para los años setenta, también se redujo la necesidad de dibujar, dada la calidad de las ilustraciones de los nuevos libros de texto. Por ello, es interesante que el recurso haya sobrevivido en estas escuelas, incluso resistiendo el uso de las pequeñas laminas impresas que tanto se pedían en las escuelas urbanas. El dibujo permitía representar temas que no tenían cabida en los programas oficiales, así como los que eran obligatorios. Maestros como Pablo, acostumbrados a hacer dibujos, de todas formas optaban por usar láminas escolares comerciales para los temas más difíciles de representar, como la evolución humana.

Lo que permaneció en la práctica de muchos maestros fue la forma de asociar la explicación verbal de un fenómeno a una imagen. Estas pautas discursivas se trasladaban fácilmente hacia la discusión de las ilustraciones de los libros y tendían a ser más abiertas que la interrogación dirigida hacia la 
comprensión del texto. En una secuencia particularmente animada, el maestro Rodrigo, después de haber dibujado un esquema del "ciclo del agua" en el pizarrón, guió la atención de los niños hacia una bella ilustración del libro que representaba un paisaje con cerros, ríos y lagos, nubes en el horizonte y lluvia en los valles, haciéndoles describir la escena y aun aceptando de ellos comentarios sobre detalles que él no había notado, como: "Detrás de las montañas también llueve", y "Estaban muy negras las nubes y acá están blancas"28.

Es difícil saber qué tanto de esta tradición que entrelazaba la plática y la explicación con el uso de dibujos y láminas se puede atribuir al IFCM y qué tanto proviene de otras fuentes. Reflejaba prácticas de los profesores del Instituto, muchos de los cuales habían sido maestros rurales en su juventud, pero incluso las prácticas del IFCM cambiaban. En una entrevista, Clementina Munive $^{29}$, quien había dirigido el Instituto durante veinticinco años, comentó las innovaciones que había intentado introducir durante los años setenta, cuando entraron los nuevos programas y libros de la llamada Reforma Educativa. Dos cambios fueron la tendencia a pedir que los maestros investigaran los temas y las llamadas dinámicas de grupo ${ }^{30}$. Pablo contaba que Clementina ponía en práctica el método de investigación y que los hacía trabajar, pero justificaba este procedimiento, "porque si yo me pongo a platicarle a mis alumnos... y no los pongo a investigar o [...] no les pongo un ejercicio... se quedan en la nada... se le olvida a uno...". No obstante, en general, Pablo, como otros de su generación, parecía tener en menor estima a los maestros que mandaban a sus estudiantes a investigar un tema en la biblioteca y luego sólo los "sacaban de dudas", renunciando a su papel central de dar clase. Efectivamente, en esa tendencia se notaba el abandono de dos recursos discursivos valorados por los maestros de la región, la plática y la explicación.

En cambio, otros maestros recuperaban las maneras más elaboradas de aplicar las 'dinámicas' promovidas por el Instituto para propiciar el trabajo en equipos y repartir las responsabilidades de la lectura del texto. Así, en cierta ocasión, Ramón organizaba a sus alumnos de sexto por equipos, para que estudiaran una lección del libro de historia y elaboraran preguntas a partir de

28 Secuencia incluida en el análisis de esta clase, en Rockwell, 1991.

29 Entrevista con C. Munive, realizada por E. Sandoval. En este caso conservo el nombre real de la maestra, por tratarse de una funcionaria con un perfil público conocido.

30 Las prácticas de investigación de temas tienen una historia larga que remonta en México por lo menos al tiempo de Rafael Ramírez, y se retomaban periódicamente.Ver Ramírez, 1937: 109-121. Las dinámicas de grupo fueron propuesta de los años setenta. 
la lectura, insistiendo que éstas estuvieran apegadas al texto y bien formuladas. En una secuencia rápida, cada equipo "lanzaba" una pregunta a otro equipo, que la tenía que contestar sin mirar el texto para ganar puntos. Ciertamente, si no había respuesta clara en la lección, el primer equipo perdía puntos. Los géneros de interrogación se habían trasladado del maestro hacia los propios estudiantes y los nuevos textos daban legitimidad a las respuestas correctas.

A lo largo de los años, se fue diluyendo la centralidad del Instituto en la formación de los maestros. El IFCM se suspendió unos años, luego se convirtió en algo distinto, para convivir con una gama de opciones de formación ${ }^{31}$. Las nuevas generaciones de maestros conocieron una mayor diversidad de propuestas. Paralelamente, se perdía la orientación que había formando ciertas tradiciones compartidas por la mayoría de los maestros de la región.

\section{Los libros “de la patria"32: reflejo y molde de una cultura magisterial}

Una de las influencias más significativas en los géneros utilizados en las escuelas mexicanas en general, así como en la región, fue la aparición de los primeros libros de texto gratuitos, que llegaron a todas las escuelas durante los años sesenta. Varios maestros de la región recordaban con cierta emoción el momento de haber recibido estos libros, ya fuera como docentes o como alumnos de primaria. En general los maestros apreciaban estos primeros libros, pues anteriormente había sido difícil lograr que todos los alumnos de la clase contaran siquiera con el mismo libro de lecturas y muchos no tenían textos. El efecto de estos libros gratuitos probablemente no fue inmediato; se filtraba a través del tiempo y los maestros de los años ochenta aún recurrían a ellos para preparar sus clases. También es posible que esos libros, escritos en general por maestros con experiencia, reflejaran una cultura docente compartida que los antecedía y que los rebasaba. Además, la estructura de lecciones de estos primeros libros influyó de manera duradera en la codificación de los contenidos escolares y en el orden que seguían muchos maestros de primaria al dar clases de ciencias sociales y naturales.

La huella más clara de estos libros era el uso del cuestionario escrito al finalizar un tema. Este género, que se encontraba al final de cada lección en

\footnotetext{
31 El IFCM fue transformado en Dirección General de Mejoramiento Profesional en 1971, y luego en Dirección General de Capacitación y Mejoramiento Profesional del Magisterio, en 1978.

32 Se conocían comúnmente como los "libros de la patria" porque traían en la portada una mujer abanderada que representaba a la Patria.
} 
muchos manuales desde el siglo XIX, probablemente sólo tomó fuerza mucho después, con la entrada de los exámenes escritos y los primeros libros gratuitos. Sólo con la disponibilidad de un mismo libro para cada niño, así como de cuadernos de trabajo que incluían cuestionarios para ser llenados por los alumnos, fue posible sistematizar esta práctica. El maestro Ramón recordaba el uso de estos libros cuando él era alumno de primaria:

... el contenido científico venía bastante amplio... y aparte cada libro traía su cuaderno de trabajo. O sea, ahí ya los niños contestábamos... en base a lo que nos explicaba el maestro... y me parecía muy bien porque traía cosas que yo digo que son elementales que sepamos... por ejemplo en Geografía... traía los paralelos, los meridianos... los límites con nuestro territorio... las temperaturas... todo eso, aunque ya no me tocó trabajar con esos libros [como maestro].

Cuando estos libros fueron sustituidos durante la Reforma Educativa de los años setenta, se eliminaron los cuadernos de trabajo para las áreas de ciencias naturales y sociales. Los maestros se sintieron obligados a poner sus propios cuestionarios para los alumnos. Para "sacar preguntas", algunos recurrían a los libros "de la patria", donde encontraban definiciones precisas, listas de atributos y esquemas taxonómicos. Aunque este tipo de contenido no aparecía con tanta fuerza en los programas vigentes, se incluían datos similares en los exámenes de ingreso a la secundaria. Los maestros opinaban que los textos de la Reforma, que se utilizaban en los ochenta, carecían de información específica sobre términos y definiciones y, por lo tanto, consultaban los viejos textos para repasar los datos pertinentes. En ese sentido, los textos "de la patria" continuaban influyendo en la práctica de los maestros, aun cuando ya no se leyeran en clase. El uso del cuestionario ha permanecido como práctica arraigada hasta la actualidad, pese a las críticas que se le hicieron ${ }^{33}$. En entrevista, Ramón admitía que antes de usar las nuevas dinámicas, "ya nada más dejábamos cuestionarios... y ya no dábamos la clase aquí directamente...con los alumnos, ya no explicábamos pues ampliamente... ahora no, ya se le está dando otro enfoque". No obstante, el cuestionario al final de la clase seguía siendo lo común en muchas escuelas.

Es posible que "los libros de la patria" también hayan moldeado ciertas maneras de hablar de los maestros. Algunos textos se asemejaban a los géneros orales que utilizaban los maestros durante los años ochenta y, sobre todo, a las valoraciones temáticas y los tonos discursivos de sus clases. Pablo segu-

\footnotetext{
33 Por ejemplo, Rafael Ramírez (1937:111) criticaba el cuestionario típico, oponiéndolo a verdaderos problemas de investigación que llevaran a una búsqueda en múltiples fuentes bibliográficas.
} 
ramente consultaba estos libros, pues aunque ya no estaban vigentes algunos ejemplares se encontraban todavía en su salón. Las coincidencias entre algunos de sus comentarios sobre los bosques y las lecciones sobre recursos naturales de los libros "de la patria" no se referían tanto a la información científica como a la formulación y valoración discursiva. Por ejemplo, el libro de sexto contenía varias páginas con una larga lista de beneficios de los árboles y una descripción idílica y moralizante de los bosques: "Además, son útiles los bosques porque albergan multitud de animales, les proporcionan alimento y los protegen contra las inclemencias del tiempo, y ante el ataque de muchos de su enemigos, entre ellos el hombre". El libro de quinto de esa época denunciaba a quienes hubieran talado los bosques, ya que "ellos han acabado con la fauna de la región... han atentado contra la Patria"34. La versión que construía Pablo en clase revelaba un tono similar.

Pablo: ... a ver, acuérdense... entonces... cuando lo vimos... lo vimos lo de los ecosistemas... yo les dije... que aquí en la Malinche... anteriormente hace... algunos años... cuando yo todavía no nacía... la Malinche... en la Malinche se contaba con una fauna... muy bonita... ¿qué quiere decir fauna?

As: ... animales...

Pablo: ... había animales... ¿verdad? ... animales como el lobo... ¿qué más había?

As -diferentes voces-: ... ¡el lobo! ¡el venado! ¡el coyote! ¡los pájaros! ¡las plantas!

Pablo: ... "¡los pájaros! ... muy esplendorosos... ahora díganme... si en esta actualidad ya la hay...

As -a coro-: ¡nooo!

Pablo: no ... antes la Malinche estaba todavía llenecita de árboles... todo estaba poblado de árboles... ¿díganme si ahora hay?

As -a coro-: ¡nooo!

Pablo: ... ni existen esos animales... ¿sigue existiendo toda la arboleda que hay?

As: ¡nooo!

Pablo: claro que no... ¿quién la extinguió?... o ¿quiénes la están extinguiendo?

As -dan varias respuestas inaudibles-.

Pablo: ... el mismo... ¡ hombre!

As -con el maestro-: ¡hombre!

Pablo: ... y ahorita, desde ahora... ¿qué deben de hacer?...

As -varios-: ... cuidar los árboles... no talarlos...

Pablo: ...no talarlos...

En cambio, este género discursivo contrasta con la versión más formal y neutral de los libros de texto de la Reforma Educativa que tenían los alumnos en la clase observada. En la lección sobre los bosques, aparecen por ejemplo los siguientes textos.

\footnotetext{
34 Mi Libro de Sexto Año. Estudio de la Naturaleza. 1971. México: SEP-Conaliteg, 41. Mi Libro de Quinto Año. Estudio de la Naturaleza. 1971. México: SEP-Conaliteg, 143.
} 
Los bosques son de gran utilidad para el hombre. Investigación 1: Haz una lista de cosas útiles que se obtienen de los bosques...

En muy poco tiempo podemos destruir un bosque... pero volver a recuperarlo tarda muchos años y a veces es casi imposible lograrlo...

Antes de talar un bosque es importante averiguar si el terreno es útil para la agricultura permanente. Si no es así, lo más conveniente es conservar el bosque ${ }^{35}$.

En esta secuencia de clase, Pablo utilizó otro recurso, al aterrizar en el contexto local la información general del texto impreso. Para ello, evocó en la plática expresiones que eran comunes en la región, seguramente conocidos por los alumnos, acerca de cómo habían sido anteriormente los bosques del volcán de La Malintzi. En muchas conversaciones con habitantes mayores de la región había escuchado el relato acerca de la pérdida de flora y fauna silvestre y del agua por la destrucción de los bosques. Las versiones se expresaban en términos muy similares a los que usó Pablo, constituyendo una especie de género local. El nexo entre el libro de texto y la tradición oral permanecerá oscuro, pero en todo caso había un antecedente importante en los libros "de la patria" que legitimaba la inclusión del relato sobre los bosques de la Malintzi en clase.

\section{Los libros de la Reforma: dilemas del descubrimiento}

Durante la Reforma Educativa de los años setenta, grandes equipos de académicos, maestros e ilustradores contratados por la Secretaría de Educación Pública produjeron los libros oficiales que aún eran vigentes en las escuelas durante el periodo del estudio ${ }^{36}$. Resulta difícil calibrar la influencia de los libros de texto de la reforma sobre las prácticas de enseñanza. Si bien los maestros en la época expresaban sus reacciones y críticas ante esta reforma, pues muchos preferían los libros 'de la patria', también era evidente la apropiación cotidiana que hacían de los nuevos textos en las clases y el respeto a la secuencia temática que marcaban. En muchos aspectos, los maestros necesariamente trabajaban con una versión sincrética, retomando formulaciones, datos e ilustraciones de los anteriores libros para ampliar sus explicaciones de los temas de los nuevos libros. Esto fue particularmente evidente en los temas de la gramática, que se había transformado bajo la influencia de la lingüística estructural, y de las operaciones aritméticas, convertidas en compli-

\footnotetext{
35 Libro de Texto de Ciencias Naturales. Sexto grado. 1982. México: Conaliteg, 41 y 44.

36 A principios de los años ochenta, se modificaron sustancialmente los libros de primero a tercero. Sin embargo, seguían sustancialmente iguales los de cuarto a sexto.
} 
cadas representaciones correspondientes a las "matemáticas modernas". Los libros en estas materias tenían tanto lecciones como ejercicios para ser llenados por los niños. No era raro que los maestros pasaran alumnos al pizarrón a resolver a la vieja usanza los ejercicios programados, para luego transferir a éstos los resultados a los nuevos libros. El maestro Fernando optó por esta vía después de intentar explicar, sin éxito, la manera de realizar las sumas y restas del libro. El formato introducido por la Reforma era complicado y desconocido, pues trataba de evitar el artificio de "llevar" y "tomar prestado" para convertir entre decenas y unidades. Al poner en el pizarrón los mismos ejercicios de la manera convencional, el maestro usaba conocimientos previos y convenciones vigentes en la vida cotidiana para facilitar el uso de los nuevos textos.

En el área de ciencias naturales, la reforma de los años setenta se vio favorecida por los antecedentes de la educación socialista. Por ejemplo, se reforzó la consigna de promover el pensamiento científico y crítico. Sin embargo, la reforma también había introducido innovaciones inquietantes. Un aspecto de la reforma preocupaba particularmente a los maestros: dentro de la propuesta se encontraba la noción de que los alumnos debieran investigar las propiedades de los fenómenos naturales que se estudiaban. Si bien esta tendencia tenía antecedentes en la formación docente en el IFCM, llevarlo a la práctica en la primaria planteaba problemas considerables. Además, ahora se trataba de hacer experimentos y actividades, no de buscar referencias al tema en la biblioteca. Ello parecía privilegiar de nuevo el plano de la interacción verbal como medio para enseñar. Sin embargo, al proponer las investigaciones como un método para enseñar las ciencias, los libros parecían desestimar la necesidad de explicar el tema a los niños.

Los nuevos libros se basaban en los métodos de descubrimiento favorecidos por la pedagogía internacional de la época. Proponían situaciones en que los alumnos mismos debían realizar experimentos y contestar preguntas, antes de que se les diera la información correspondiente. Un procedimiento análogo era la indicación de dejar que los niños se aproximaran directamente a los libros, sin mediación docente, para comprender el texto. Como efecto de la diseminación de esta metodología, en algunas clases los maestros decían que intentaban "sacar de los propios niños" las conclusiones. Al adoptar esta consigna, los maestros renunciaban a exponer o ampliar el texto y preferían interrogar a los alumnos sobre lo que ellos comprendían de la experiencia, o directamente de la lección ${ }^{37}$. 
A pesar de los esfuerzos por seguir el nuevo lineamiento, los maestros enfrentaban complicaciones en clase. La lección introductoria del libro de cuarto presentaba el sentido de la investigación a partir de una versión del relato hindú en el que varios ciegos tocan diferentes partes de un elefante y luego tratan de ponerse de acuerdo sobre cómo era el animal. La maestra Malena hábilmente intentó relatar el cuento, exagerando los detalles y el suspenso para hacer comprender a los niños el sentido de descubrir. Sin embargo, los alumnos tenían el libro abierto y se dieron cuenta desde el inicio que se trataba de un elefante. Por lo tanto, fue muy difícil para la maestra lograr el efecto deseado, que los niños asociaran la lección con el procedimiento científico $^{38}$.

En las clases observadas, una tendencia común era simplificar las actividades experimentales, o dejarlas de tarea, por carecer de condiciones para realizarlas en clase. Otra era abordar los experimentos sugeridos con discusiones virtuales en la clase. Por ejemplo, en la clase sobre el tema del sonido, con la ayuda de las ilustraciones del libro, el maestro Valentín pidió a los alumnos que imaginaran y opinaran cómo sería el sonido producido al jalar una cuerda, sujetada en una tabla entre dos clavos, según estuviera más estirada o menos estirada. Imaginar lo que resultaría de un experimento constituía todo un reto, que apelaba necesariamente a saberes que los niños hubieran adquirido en la vida diaria. A menudo, incluso las actividades que se realizaban en clase no conducían a una conclusión clara, lo cual también resultaba preocupante para los maestros, dada las valoraciones pedagógicas locales.

En situaciones de ambigüedad, los maestros volvían a la seguridad del saber escolar consolidado o bien volvían al texto. Al inicio de la clase sobre el ciclo del agua, el maestro Rodrigo intentaba recabar información sobre una investigación sugerida por el texto que les había dejado de tarea a los niños. Les había pedido que construyeran una veleta y observaran en qué dirección soplaban los vientos locales. Cuando él preguntó a los alumnos acerca de los resultados, se suscitó una discusión entre ellos. Resultó que ellos habían hecho la investigación a diferentes horas y tenían diferentes resultados; además, unos alegaban que otros no lo habían hecho bien. El maestro, quien no vivía en el poblado, carecía de información para mediar entre los alumnos y, por tanto, optó por

37 Ver Rockwell, 1995, en donde analizo dos clases que contrastan en este sentido.

38 En Rockwell, 2001a, analizo esta clase. 
dejar inconclusa la discusión y preguntar acerca de los usos del agua. La utilidad del agua no era tema del texto; hacía eco de la tradición de enseñanzas prácticas y las recomendaciones de los libros anteriores.

Algo similar sucedía cuando los maestros enfrentaban las preguntas directas al lector que aparecían dentro del texto mismo y que invitaban a suspender la lectura y a pensar en algún fenómeno natural conocido. Por ejemplo, al principio de la lección sobre ecosistemas, antes de dar información, se incluyen preguntas como: “¿Recuerdas algunas características de las plantas que viven donde hay poca agua?" 39 . En algunas clases, los maestros ignoraban este cambio de registro en el texto. Proseguían con la lectura en voz alta hasta el final de la lección y, en todo caso, recuperaban las preguntas dentro del cuestionario final de su propia factura. Este manejo no siempre resultaba, porque la pauta acostumbrada para los cuestionarios era formular una pregunta que tuviera una respuesta clara dentro del texto mismo. Las preguntas de los nuevos libros de ciencias rompían con ese molde, pues a menudo no tenían respuesta dentro del texto; se incluían para que los alumnos expresaran su experiencia o formularan conclusiones a partir de un experimento. Algunos maestros, sin embargo, detenían la lectura y retomaban la pregunta propuesta en el texto y trabajaban con el grupo en la construcción de una respuesta elaborada colectivamente. En la clase sobre el ciclo del agua, el maestro Rodrigo dedicó un buen rato a una pregunta planteada -sin respuesta- en el texto: “¿Por qué crees que cuando hay tormentas en las costas puede llover en algún lugar del centro de la República?" Con la ayuda del mapa del país y varios esquemas dibujados en el pizarrón, preguntaba a los niños y les explicaba hasta asegurarse que hubieran asociado las tormentas, la dirección de los vientos, la costa y las cordilleras con el arribo de las lluvias al centro del país ${ }^{40}$. Por ejemplo, mientras agrega flechas en el dibujo en el pizarrón, del mar hacia la cordillera, dice: "Estas vienen del mar...fíjense que estos vientos van a ocasionar que estas nubes choquen con las montañas... y provoquen tormentas....". En estos casos, era palpable el efecto potencial de los nuevos libros sobre la textura genérica del discurso docente, sin embargo, también era evidente la necesidad de incorporar todo un arsenal propio de recursos discursivos y pedagógicos para poder trabajar con los nuevos textos.

\footnotetext{
39 Libro de Texto de Ciencias Naturales. Sexto año. 1982. México: Conaliteg, 10.

40 En Rockwell, 1991, analizo esta secuencia.
} 
La pedagogía del descubrimiento y de la reflexión sobre la experiencia parecía requerir nuevas herramientas discursivas, más allá de los recursos que permanecían vigentes de la enseñanza objetiva. Ciertamente, no eran sólo los maestros de esta región quienes enfrentaban los problemas de usar este método. En un estudio realizado en Inglaterra, los autores notaron "el dilema que enfrentan los maestros al tener que inculcar conocimientos mientras aparentemente estarlos elicitando" (Edwards y Mercer, 1987: 126), frase que hace eco de la consigna pedagógica que Rebsamen había emitido un siglo atrás. Esta práctica - elicitation en inglés-, entendida como el uso de todo tipo de tretas discursivas para inducir a alguien a decir lo que uno quiere que diga, resume las tensiones que aparecían a menudo cuando la intención de incorporar los saberes y las reflexiones propias de los niños entraba en conflicto con la necesidad sentida por los maestros de enseñar nuevos contenidos a sus alumnos. Ello mostraba una faceta más de la contradicción entre la apertura de la comunicación oral y la fijación del contenido en los textos escolares. No obstante, los nuevos textos no necesariamente conducían a cerrar las respuestas y las formulaciones del contenido escolar, a la manera de los antiguos catecismos y de los cuestionarios habituales. Al tomar en serio las investigaciones y las preguntas abiertas, y al propiciar la reflexión colectiva sobre las ilustraciones, los maestros abrían espacios de conversación que admitían formulaciones alternativas del conocimiento.

Durante los años ochenta, los maestros enfrentaban una nueva situación en las aulas, en la que ellos ya no se podían considerar los portadores privilegiados del conocimiento a ser transmitido. Los nuevos libros, especialmente en el área de ciencias, planteaban retos importantes al pretender combinar la experiencia de los niños, los textos impresos y la voz del maestro como fuentes complementarias para la construcción de conocimientos (Candela, 1999). Además, tanto los niños como los maestros se referían a información proveniente de conocimiento local o bien de la radio y la televisión. Como maestro, costaba trabajo mediar entre todas estas fuentes, dentro de condiciones institucionales que seguían requiriendo la evaluación por medio de instrumentos que valoraban respuestas únicas. Para hacer frente a este reto, los maestros seleccionaban y combinaban con diferentes grados de éxito recursos pedagógicos generados durante todo un siglo. Como consecuencia, se observaba que la presencia de los libros de texto de la Reforma en las clases, lejos de uniformar la enseñanza como algunos esperaban y otros objetaban, propiciaba muy distintas prácticas en torno al texto. 


\section{Reflexiones finales}

Los planos anteriores están lejos de agotar las corrientes que influyeron en la formación de una cultura regional de enseñanza durante el siglo XX. Además, es necesario recordar que en ningún momento esta cultura fue homogénea, siempre contenía una abigarrada combinación de géneros y voces del pasado. Son evidentes los desfases entre la introducción oficial de propuestas pedagógicas y su incorporación a la práctica cotidiana. Las formas de enseñanza cambiaron, pero gradualmente; los maestros sustituían algunos géneros preexistentes y los combinaban con otros para hacer frente a las cambiantes exigencias del sistema educativo. Además, algunos empezaban a introducir prácticas no difundidas oficialmente en esos años, como pedir a los alumnos que escribieran cuentos o grabar a los niños para que escucharan su propia lectura en voz alta. Para los años ochenta, era evidente que el discurso docente no reproducía el guión de los libros de texto oficiales vigentes en la época, sino más bien sintetizaba una construcción a largo plazo en que el conocimiento escolar se entretejía con tradiciones magisteriales y prácticas discursivas locales. En suma, las prácticas de enseñanza que resultaron hacia finales del siglo eran una amalgama de diversos modos de representación y géneros discursivos acumulados a lo largo de los años. Los mejores maestros y maestras parecían ser capaces de echar mano de recursos provenientes de muy diversas épocas y de combinarlas para subsanar las deficiencias de las sucesivas propuestas oficiales y enriquecer la enseñanza.

Sin embargo, no se trataba simplemente de un proceso de suma y resta de recursos didácticos ni de una sucesión de modas pedagógicas. A lo largo del siglo, en esta región, se habían incrementado las fuentes impresas utilizadas como recursos pedagógicos en las escuelas. En torno a los textos se tejieron diversas formas de hablar y de enseñar, generando distintas maneras de relacionarse con la palabra escrita. Si bien es difícil captarlo en su dimensión temporal, el contraste entre ciertas tendencias generacionales en el manejo del texto parece apoyar esta percepción. Una constante a lo largo del siglo había sido la tensión que emergía entre el uso de la palabra oral por los docentes y alumnos y el creciente predominio del texto impreso como fuente de conocimiento. Esta tensión era visible en la queja de algunos padres de los años ochenta acerca de maestros que se ceñían a repetir el texto: "Así cualquiera puede ser maestro" decían. Aparentemente seguía habiendo consenso de que los maestros debían dominar y poder expresar oralmente los temas escolares y saber manejar la participación en clase para que los niños "aprendieran a razonar". 
A pesar de la presencia de fuentes impresas, la valoración de la expresión oral reaparecía en numerosas clases, aun aquellas a cargo de los maestros que más utilizaban los libros de texto. El habla docente revelaba huellas de los diversos géneros orales. Si bien algunos eran calcas de referentes escritos y de codificaciones netamente escolares de los conocimientos impartidos, otros géneros, más cercanos a la conversación, abrían espacios en los que emergían versiones alternativas y saberes o expresiones locales. Los usos de la palabra oral permitían explicar y ampliar los contenidos de los libros más allá de la formulación fijada por escrito. Finalmente, el recurso del dibujo ofrecía otra modalidad de representación del contenido, básica para construir los puentes orales entre el entendimiento infantil y la formulación escrita.

El peso relativo que mantenía el uso de la palabra oral permite cuestionar la clásica identificación de la escuela con una "cultura escrita", donde predomina la enseñanza de la lengua como objeto escrito y escolar, como ha sostenido Bernard Lahire (2001: 177-199), basándose en observaciones en escuelas francesas. En las aulas observadas en México, si bien la lengua escrita, representada por una codificación particular construida para el medio escolar ${ }^{41}$, es un objeto de enseñanza importante, la realidad cotidiana muestra cómo la palabra oral puede retomar y reproducir, pero también suele ampliar, reformular, desplazar y contradecir tanto la estructura como el sentido del referente escrito ${ }^{42}$. Yo subrayaría el reto que Lahire mismo ha planteado: "es necesario entonces retomar el análisis empírico de las prácticas singulares y sólo autorizar generalizaciones prudentes y limitadas" (Lahire, 2001: 199) ${ }^{43}$. En suma, se requiere aún mucha más investigación historiográfica y comparativa para comprender las múltiples maneras en las que el trabajo escolar ha moldeado la relación con el lenguaje y el saber.

Si bien no he abordado en este artículo el vínculo entre la escuela y la cambiante sociedad circundante, es claro que la relación no sería lineal. Subrayo la falacia de inferir a partir de documentos normativos de una época la impronta que puede haber dejado la escuela sobre las personas que la cursaron, sin realizar el análisis de las prácticas culturales cotidianas en las aulas y en los contextos inmediatos. Es necesario apreciar el impacto de las reformas oficiales dentro de realidades escolares conformadas por una compleja

\footnotetext{
41 Véase Chervel, 1998 y Viñao, 1999.

42 Creo que la versión de Lahire puede ser más certera para las escuelas francesas que las mexicanas, según las observaciones preliminares que yo he realizado en primarias en París.

43 Traducción de la autora.
} 
red social y cultural antecedente, que las recibe, reformula, desecha o aplaza. La influencia de las medidas políticas es imprevisible a priori y desde arriba; puede ser efímera o bien puede perdurar más allá de su vigencia oficial. Un caso clave en México es el de la educación socialista, de breve vigencia, que para algunos significó la imposición efectiva de una nueva ideología, y para otros fue inexistente o fugaz en las escuelas. En esta región, esa reforma no fue difundida con particular empeño y, no obstante, dejó marcas que durarían décadas, cifrándose en disposiciones docentes que no eran identificables a primera vista como socialistas, pero que se distinguen en el conjunto de reformas del siglo.

Esta perspectiva contrasta con la de ciertos discursos sobre la historia de la educación formal, que tienden a confiar en las versiones públicas elaboradas por las propias instituciones y los poderes estatales. Es común inferir a partir del discurso normativo de un régimen, por ejemplo el franquismo, la conformación de determinado tipo de sujeto, sin considerar las complejas mediaciones y los entramados culturales preexistentes que en efecto moldean la experiencia escolar. Se hace abstracción de las vicisitudes y sedimentaciones evidentes en las prácticas docentes cotidianas en cualquier corte temporal, así como los márgenes, siempre variables, de acción autónoma que tienen los maestros ${ }^{44}$. Sólo con estudios antropológicos que aborden la vida cotidiana en las aulas y ubiquen los puntos de coerción y consenso que pudieran hacer efectivas las prescripciones oficiales, será posible explorar las consecuencias ideológicas y subjetivas de los mandatos decretados desde el poder.

Acostumbrarse a mirar lo que ocurre en las aulas en estos términos constituye un primer paso para poder sopesar la influencia real que pudieran tener las políticas educativas en la configuración de ideologías, identidades y culturas nacionales. Los decretos oficiales se filtran a través de numerosas instancias de mediación antes de integrarse, siempre parcial y provisionalmente, a las complejas culturas escolares. Ahí, siempre compiten con corrientes presentes en los entornos sociales y culturales -desde la tradición oral hasta la expansión de los medios de comunicación- que también influyen en el horizonte cultural y dan sentido a la experiencia escolar.

Algunos autores subsumen la diversidad de prácticas escolares bajo conceptos como "la gramática escolar", o "la forme scolaire", supuestamente generalizables a toda experiencia escolar moderna (Tyack y Cuban, 1995;

44 Véase Escolano, 2000. 
Vincent, 1994). Desde cierta escala de análisis, haciendo abstracción de diferencias, estos conceptos muestran que gran parte de los lugares llamados "escuela" se caracterizan entre otras cosas por un régimen piramidal y competitivo y por una relación pedagógica vertical y descontextualizada, referida a textos normativos oficiales. Sin embargo, bajo esta estructura común se tejen relaciones con una diversidad de géneros discursivos orales y escritos, que expresan tanto el saber escolar legítimo como el saber fundamentado en la experiencia de los sujetos, generando representaciones e interpretaciones netamente locales. La aproximación antropológica aconsejaría más bien realizar el arduo trabajo de comparación entre prácticas escolares predominantes en diferentes lugares/tiempos, tomando siempre en cuenta las configuraciones culturales e históricas en sus entornos. Considero que desde una perspectiva que enfatice la diversidad, aparecerían muchos fenómenos interesantes, con signos muy distintos entre sí.

\section{Referencias bibliográficas}

ANDERSON-LEVITT, Kathryn M.

2002 Teaching Cultures: Knowledge for Teaching First Grade in France and theUnited States. Cresskill, New Jersey: Hampton Press.

BAJTíN, Mijail [Bakhtin, Mikhail]

1982 "La novela de educación y su importancia en la historia del realismo", en Estética de la creación verbal. México: Siglo XXI, 200-247.

1984 Problems of Dostoevsky's Poetics. Minneapolis: University of Minnesota Press.

1986 "The Problem of Speech Genres", en C. Emerson y M. Holquist (eds.), Speech Genres and Other Late Essays. Austin: University of Texas Press, 60-102. En español, Bajtín, Mijail. 1982, "El problema de los géneros discursivos", en Estética de la creación verbal. México: Siglo XXI, 248-293.

BENJAMIN, Walter

1999 Selected writings. Vol. 2. 1927-1934. Cambridge, Massachusetts: Belknap Press of Harvard University Press.

CANDELA, Antonia

1999 Ciencia en el aula: los alumnos entre la argumentación y el consenso. México: Paidós.

CARRILLO, Carlos A.

1964 [1907] "Libro de Texto", en Artículos Pedagógicos. Biblioteca Pedagógica 
de Perfeccionamiento Profesional 34. México: Secretaría de Educación Pública, Instituto Federal de Capacitación del Magisterio, 96-100.

CHARTIER, Anne-Marie

2003 Enseñar a leer y escribir. México: Fondo de Cultura Económica.

2005 "L'école entre crise des croyances et crise des pratiques. L'exemple de la lecture à voix haute", en F. Jacquet-Francillon y D. Kambouchner (dirs.), La crise de la culture scolaire. Paris: PUF, 227-261.

CHARTIER, Anne-Marie; HEBRARD, Jean

1989

Discours sur la lecture (1880-1980). Paris: Centre G. Pompidou (réédition augmentée (1880-2000). 2000. Paris: BPI-Fayard). En español, Discurso sobre la lectura. 1994. Barcelona: Gedisa.

CHERVEL, Andre

1998 La culture scolaire: une approche historique. Paris: Belin.

EDWARDS, Derek; MERCER, Neil

1987 Common Knowledge. London: Routledge. En español, El conocimiento compartido. 1988. Barcelona: Paidós.

ESCOLANO, Agustín

2000

"Las culturas escolares del siglo xx. Encuentros y desencuentros". Revista de Educación, Núm. Extraordinario: 201-218.

FLORES, Manuel

1901 [1884] Tratado elemental de pedagogía. $3^{\text {a }}$ ed. México: Ch. Bouret.

GONZÁLEZ, Enrique (Coord.)

1982 Los Libros de Texto Gratuitos. México: Secretaría de Educación Pública. Comisión Nacional de los Libros de Texto Gratuitos.

KRESS, Gunther R; JEWITT, Carey; et al.

$2001 \quad$ Multimodal Teaching and Learning. Harrisburg, Pennsylvania: Continuum International Publishing Group.

JULIA, Dominique

1995 "La culture scolaire comme objet historique", en A. Nóvoa, M. Depaepe y Erwin V. Johanningmeier (eds.), The Colonial Experience in Education, Historical Issuesand perspectives, Paedagogica Historica. Supplementary Series Volume I. Gent: CSHP, 353-382. 
LAHIRE, Bernard

2001 "Ecole, action et langage", en B. Lahire, L'homme pluriel. Les ressorts de l'action. Paris: Armand Colin/Nathan, Hachette, 177-199.

LAWN, Martin; GROSVENOR, Ian

2005 Materialities of Schooling. Oxford: Symposium.

NESPOR, Jan

1997

Tangled up in School: Politics, Space, Bodies and Signs in the Educational Process. Mahwah, New Jersey: Lawrence Erlbaum Associates.

RAMÍREZ, Rafael

1937 Curso de Técnica de la enseñanza. Para el uso de escuelas regionales. México: DAPP.

1986 Rafael Ramírez y la escuela rural mexicana. Compilación de textos de R. Ramírez por C. Jiménez Alarcón. México: El Caballito.

RAZO, José Antonio

2000 "Catecismo civil" (1827). Tiempo de educa, 2,3-4:191-228.

REBSAMEN, Enrique C.

2001 Obras Completas, Vol. 1. Compilación de A. J. Hermida Ruiz. Xalapa, Veracruz: Secretaría de Educación y Cultura del Gobierno del Estado de Veracruz.

ROCKWELL, Elsie

1991 "Palabra escrita, interpretación oral: los libros de texto en la clase". Infancia y Aprendizaje, 55: 29-43.

1995 "En torno al texto: tradiciones docentes y prácticas cotidianas", en E. Rockwell (coord.), La escuela cotidiana. México: Fondo de Cultura Económica, 198-222.

1997 "La dinámica cultural en la escuela", en Amelia Álvarez (ed.), Hacia un currículum cultural. La vigencia de Vygotski en la educación. Madrid: Infancia y Aprendizaje, 21-38.

1999 "Recovering history in the study of schooling: from the longue durée to everyday co-construction". Human Development, 42, 3: 113-128.

2000 "Teaching Genres: A Bakhtinian Approach". Anthropology and Education Quarterly, 31, 3: 260-282.

2001a "La lectura como práctica cultural: perspectivas históricas sobre libros escolares". Educação e Pesquisa, 27-01: 11-26. Sao Paulo. En francés: "La lecture en tant que pratique culturelle: concepts pour l'étude des livres scolaires". Education et Sociétés, 17: 29-48. 
2001b "The Uses of Orality and Literacy in Rural Mexico: Tales from Xaltipan", en D. R. Olson y N. Torrance (eds.), The Making of Literate Societies. Oxford: Blackwell, 225-247.

2002 "Learning from life or learning from books: reading practices in Mexican rural schools". Paedagogica Historica, 38, 1: 113-135. En español, "Entre la vida y los libros: prácticas de lectura en las escuelas de la Malintzi a principios del siglo XX". 2004, en C. Castañeda, L.E. Galván y L. Martínez (coords.), Lecturas y lectores en la Historia de México. México: Centro de Investigación y Estudios Superiores en Antropología Social, 327-357.

2007 Hacer escuela, hacer estado. Zamora, México: El Colegio de Michoacán, CIESAS y CINVESTAV.

SEWELL, William

2005 Logics of History. Social Theory and Social Transformation. Chicago: University of Chicago Press.

TANCK DE ESTRADA, Dorothy

1977 La educación ilustrada. 1786-1836. México: El Colegio de México.

TYACK, David; CUBAN, Larry

1995

Tinkering toward Utopia: A Century of Public School Reform. Cambridge, Massachusetts: Harvard University Press.

VINCENT, Guy

1994 L'Education prisonnière de la forme scolaire. Lyon: Presses Universitaires de Lyon.

VIÑAO, Antonio

1999

Leer y escribir. Historia de dos prácticas culturales. México: Educación, voces y vuelos, IAP. 